\title{
Uma associação entre o artesanato, o poder público local e os comerciantes do município de Itajubá, sul de Minas Gerais
}

\section{A association between handicraft, local government and traders in the municipality of Itajubá, southern Minas Gerais}

Juliana Boldrin - Mestra em Desenvolvimento, Tecnologias e Sociedade, pela Universidade Federal de Itajubá (UNIFEI). E-mail: julianaboldrinadm@gmail.com

Tayrine Parreira Brito - Doutoranda em Engenharia Agrícola, pela Universidade Estadual de Campinas (UNICAMP). E-mail: tayrinepb@gmail.com

Viviane Guimarães Pereira - Doutora em Administração na linha de Desenvolvimento, Gestão Social e Ambiente, pela Universidade Federal de Lavras (UFLA). Professora na Universidade Federal de Itajubá (UNIFEI). E-mail: vivianeguimaraespereira@unifei.edu.br

\section{Resumo}

As feiras de artesanato possuem um papel de importância social, histórica, cultural e econômica nos contextos em que estão inseridas. Itajubá, município no sul de Minas Gerais, possui a feira de artesanato da Associação Artes da Terra (AAT), originada em 2001 e que atualmente conta com 26 associadas e associados e está localizada na praça Getúlio Vargas, local este que possui algumas demandas de melhorias e que hoje os membros da AAT necessitam da mudança de localidade da feira. Com isso, a presente pesquisa tem por objetivo analisar a partir de uma perspectiva feminista a ocupação pública e social da feira das mulheres da Associação Artes da Terra na Praça Theodomiro Santiago e a sua interação com o comércio fixo local e o poder público $\mathrm{e}$, posteriormente, analisar as relações com o poder público municipal. Para o melhor alcance desses objetivos, foram utilizadas como percurso metodológico entrevistas semiestruturadas com 18 comerciantes do entorno da praça Theodomiro Santiago.

\section{Palavra-chave}

Feiras de Artesanato. Associação Artes da Terra. Itajubá. Comerciantes Locais e Poder Público.

\begin{abstract}
Craft fairs play a role of social, historical, cultural and economic importance in the contexts in which they operate. Itajubá, a city in the south of Minas Gerais, has the arts fair called Associação Artes da Terra (AAT), originated in 2001, actually has 26 associates and is located at Praça Getúlio Vargas, a place that has some demands for improvements and that today is mandatory to change the location of the fair. Thus, the present research aims to analyze from a feminist perspective the public and social occupation of the arts fair from Associação Artes da Terra at Praça Theodomiro Santiago and its interaction with the local fixed commerce and the public power and, subsequently, analyze the relations with the municipal public power. For the best achievement of these objectives, the methodology used were semi-structured interviews with 18 traders from around Theodomiro Santiago square.
\end{abstract}

\section{Keywords}

Handicraft Fairs. Associação Artes da Terra. Itajubá. Merchants Around and Municipal Government. 


\section{INTRODUÇÃO}

A Associação de Artesãos Artes da Terra (AAT) é formada por um grupo de artesãos e artesãs que se organizam em uma feira para a comercialização coletiva, composta majoritariamente por mulheres. A AAT teve origem em 2001 e desde então realiza a feira semanalmente na praça Getúlio Vargas, no município de Itajubá, no sul de Minas Gerais.

O local de ocorrência da feira é alvo de intensas discussões entre as(os) $\operatorname{associadas}^{1}(\mathrm{os})$ da AAT e o poder público local. Para as associadas, o local não é favorável para as vendas e por isso estão sempre buscando outros pontos da cidade que acreditam ter maior potencial. E o principal desses pontos é a praça Theodomiro Santiago, considerada a praça central da cidade. O espaço almejado para a feira é aparentemente o ponto de maior circulação do município de Itajubá, pois em seu entorno estão localizados diferentes tipos de estabelecimentos comerciais como lotérica, lojas de móveis, loja de celulares, de venda de viagens e de alimentação (sorveteria, pastelaria, lanchonetes, bares e restaurantes).

É importante destacar que historicamente as mulheres foram excluídas da formação dos espaços públicos. Essa exclusão auxiliou na formação de espaços que não englobassem as construções sociais e culturais das diferentes mulheres, desenvolvendo, assim, alguns locais rodeados por violências e/ou silenciamentos, descortinando um papel mercadológico e não usual dos espaços públicos, diante do qual é necessária uma reformulação dos locais a fim de incluir as mulheres.

A ocupação dos espaços públicos também tem realização histórica com a invisibilidade dos trabalhos realizados por mulheres. Durante a consolidação do sistema capitalista, os corpos das mulheres foram utilizados de maneira a gerar novas mãos de obra e novas mercadorias. Na maioria das vezes, as atividades que antes eram por elas lideradas acabaram sendo marginalizadas ou até mesmo invisibilizadas.

Realizando um paralelo com o local ocupado pelas mulheres da AAT, havia uma importância comercial e social na ocupação do espaço da praça central, a fim de aumentar não somente as vendas, mas também obter uma maior visibilidade

\footnotetext{
Tendo em vista que a Associação Artes da Terra é composta majoritariamente por mulheres, dentro do texto é utilizada a palavra associada se referindo tanto a membros homens e mulheres da associação. Cabe destacar também que este artigo traz uma linguagem crítica sobre a questão de gênero, destacando uma questão linguística, social, cultural e política sobre as mulheres. Costa (2002) menciona que a mulher é formada pelos signos existentes em toda a sociedade. Por esta razão, as palavras "membras" e "sujeitas" - consideradas como substantivos femininos, no plural, dos termos "membros" e "sujeitos", conforme o Vocabulário Ortográfico da Língua Portuguesa (ABL, 2009) - serão mencionadas neste texto não simplesmente no sentido linguístico para esses dois substantivos, mas também com um sentido cultural, social e político a fim de ressignificar palavras.
} 
para o trabalho realizado pelas associadas. Em certos momentos, o poder público cedeu à AAT a realização da feira na praça Theodomiro Santiago, quando houve um aumento significativo das vendas realizadas. Contudo, depois de algum tempo o poder público passou a recusar a realização do evento no local, alegando que o comércio ao entorno não estava favorável, justificando que houve reclamações e enfatizando que o local cedido para a AAT é a praça Getúlio Vargas.

Diante disto, o objetivo do presente trabalho é analisar a partir de uma perspectiva feminista a ocupação pública e social da feira das mulheres da Associação Artes da Terra na praça Theodomiro Santiago e a sua interação com o comércio fixo local e o poder público. Além disso, a proposta é que esta pesquisa também sirva de subsídio para a AAT dialogar com o poder público municipal de Itajubá.

A base teórica deste trabalho foi construída a partir das discussões da atuação da mulher no mundo do trabalho, uma vez que as mulheres são a maioria das associadas da AAT, juntamente com o trabalho artesanal e as feiras enquanto espaços públicos. Vale ressaltar que a presente pesquisa é também o desdobramento de uma dissertação de mestrado, desenvolvida no Programa de Pós-Graduação em Desenvolvimento, Tecnologias e Sociedade, na Universidade Federal de Itajubá, que buscou analisar de que maneira as sujeitas da Associação Artes da Terra se interagem na busca de alternativas em geração de renda.

Além desta introdução, o texto foi dividido em outras cinco partes: a primeira sobre o percurso metodológico, a segunda sobre a caracterização do local da pesquisa, a terceira trata das dimensões sociais do trabalho artesanal da Associação Artes da Terra, a quarta parte é referente às feiras e suas expressões culturais, sociais e econômicas e, por fim, a quinta e última parte apresenta as considerações finais.

\section{PERCURSO METODOLÓGICO}

A pesquisa é construída de acordo com a visão de quem a realiza, sendo assim há uma interferência de acordo com o espaço social e cultural vivenciado. Este trabalho foi desenvolvido segundo as metodologias feministas, de modo a dar protagonismo para as sujeitas da pesquisa e elucidar que, muitas vezes, a presença das pesquisadoras pode alterar os elos sociais (NARVAZ; KOLLER, 2006).

Vale destacar que há inúmeras maneiras de esboçar o conhecimento tendo como partida diferentes teorias, o que pode se materializar em diversos resultados de pesquisa, sendo de acordo com a ótica de quem está realizando. Ou seja, segundo Haraway (1995), a pesquisa científica é situada. 
O Brasil é um país ancorado pelos pilares do patriarcado, que reverbera em todas as esferas sociais, políticas e econômicas. $\mathrm{Na}$ esfera de produção científica é notada uma interferência dessas bases na produção, o que traz a importância do atual trabalho na apresentação de uma atividade realizada juntamente com mulheres artesãs. Harding (1993) menciona que, ao pesquisar atividades que mulheres vivenciam, há a possibilidade de apresentar elementos que normalmente são invisibilizados pelo sistema capitalista.

O caminho metodológico deste artigo se iniciou em abril de 2018 e partiu de uma demanda apresentada por uma organização social que é a AAT, durante as diversas atividades (assembleias e oficinas) nas quais as pesquisadoras participaram junto às associadas.

O instrumento metodológico utilizado foi a entrevista semiestruturada, guiada pela pesquisa realizada por Ribeiro (2007), sobre as feiras do Vale do Jequitinhonha, e a pesquisa realizada por Pereira et al. (2016) na feira de Conceição do Mato Dentro, Minas Gerais. Assim, para esta pesquisa, foram entrevistados os responsáveis por todos os comércios localizados ao entorno da praça Theodomiro Santiago (Quadro 1).

Quadro 1 - Empreendimentos/comércios que foram entrevistados

\begin{tabular}{|c|l|l|}
\hline \multicolumn{2}{|c|}{ Nome do empreendimento/comércio } & \multicolumn{1}{c|}{ Setor de atuação } \\
\hline 1 & Five Star & Bar \\
\hline 2 & Bomboniere Aquário & Alimentação \\
\hline 3 & Vera Cruz Florarte & Eletrodomésticos e móveis \\
\hline 4 & Vivo & Telefonia \\
\hline 5 & Eletrolar & Móveis \\
\hline 6 & CVC & Viagens e turismo \\
\hline 7 & Sorveteria do Mauro & Alimentação \\
\hline 8 & Central Lotérica & Lotérica \\
\hline 9 & Sorveteria Salutti & Alimentação \\
\hline 10 & Sorveteria Deliciosa & Alimentação \\
\hline 11 & Churras Vadinho & Alimentação \\
\hline 12 & Bithome & Informática \\
\hline 13 & Butekos & Alimentação \\
\hline 14 & Amazon Açaí & Alimentação \\
\hline 15 & Cantina Tati & Alimentação \\
\hline 16 & Coxinharia & Alimentação \\
\hline 17 & Ilha do Pastel & Alimentação \\
\hline 18 & Fratelli & Alimentação \\
\hline
\end{tabular}

Fonte: Elaborado pelas autoras. 
No total, foram entrevistados(as) dezoito proprietários(as) de estabelecimentos comerciais. As indagações se pautavam em investigar se havia alguma mudança no movimento do comércio nos dias em que ocorria a feira; se a feira da AAT atraía mais clientes para as lojas; quais seriam os benefícios e os malefícios de a feira ser realizada na praça e, por fim, se havia alguma sugestão de melhoria para a feira da AAT. Por meio dessas entrevistas semiestruturadas foi possível realizar parte das análises do texto e a construção dos gráficos e quadros apresentados no artigo.

\section{CARACTERIZAÇÃO DO LOCAL DE PESQUISA}

O município de Itajubá, localizado na região Sul do estado de Minas Gerais, conta com uma população de 96.389 habitantes, distribuídos em uma área territorial de $294.835 \mathrm{~km}^{2}$. Seu Produto Interno Bruto (PIB) corresponde a R $\$ 27.397,44$. Contudo, o valor médio do salário mensal de trabalhadores e trabalhadoras é de 2,7 salários mínimos e somente $29,2 \%$ da população se encontra na posição ocupada, ou seja, exercem trabalhos formais. Assim, quando comparado com os dados de porcentagem da população que possui até meio salário mínimo, esse número se torna ainda mais expressivo, chegando a 33,2\% (IBGE, 2018).

Diante deste contexto de desigualdade existente no município, surge a importância da realização de alternativas para trabalho e renda da população que não faz parte dos 29,2\%. Destaca-se assim o artesanato com a presença hoje no município de duas associações compostas por aproximadamente 30 famílias cada uma.

A Secretaria Municipal da Cultura e Turismo (SECUT) é o órgão público mais próximo das atividades artesanais em Itajubá. A SECUT tem a missão de colocar em prática a política de desenvolvimento cultural conjuntamente com a população, de elaborar tarefas de preservação dos bens históricos, além de realizar iniciativas e atividades ligadas ao turismo.

De acordo com Lemos (2011), o artesanato hoje não deve ser visto como uma atividade econômica marginal, e sim com um potencial competitivo de mercado, não no sentido da exploração de recursos, mas de inserção e relevância econômica. Em muitos países europeus a qualidade dos produtos artesanais supera a qualidade dos de alto valor agregado.

Ferreira Júnior, Nascimento e Figueiredo (2016) argumentam que o saber e fazer do trabalho artesanal passa por um processo único de diversos procedimentos e meios sociais e práticos, e busca desenvolver alternativas para o compartilhamento e convívio desses conhecimentos entre as artesãs e os artesãos. 
O artesanato pode ser dividido em duas vertentes: 1) uma tradicionalista que defende o artesanato como um movimento artístico que perpetua tradições sociais e, 2) a vertente mercadológica que menciona que artesanato necessita de modificações de estrutura e aparência para se adequar ao mercado e desta maneira garantir a sua multiplicação (LEITE, 2005). Ambas as vertentes se intersecionam com as relações políticas, sociais e econômicas das artesãs e dos artesãos.

$\mathrm{Na}$ Finlândia e na Dinamarca, por exemplo, os artesanatos são altamente sofisticados, contudo, são países que incentivam o trabalho artesão, promovendo políticas de valorização dessa prática e proporcionando abertura de mercados (LEMOS, 2011).

No contexto brasileiro, Grimm, Sampaio e Procopick (2018) mencionam que cada município possui as suas próprias características para a formação de Políticas Públicas, que são construídas de acordo com o contexto local e com que os gestores entendem ou não como prioridade. Em Itajubá não existem políticas direcionadas ao artesanato. A SECUT, que é o órgão gestor mais próximo, coloca o artesanato no balaio das ações culturais, considerado, assim, sem expressão econômica e com o viés de entretenimento.

\section{DIMENSÕES SOCIAIS DO TRABALHO ARTESANAL DA ASSOCIAÇÃO ARTES DA TERRA}

Segundo o Regimento Interno de Funcionamento da Associação Artes da Terra (AAT, 2017), ela foi criada em 11 de maio de 2001 e até a data desta pesquisa era composta por vinte e seis associados(as), e dividida em dois setores: artesanato e alimentação, sendo que cinco mulheres e cinco homens participavam do setor de alimentos e quatorze mulheres e dois homens do setor artesanal. No geral são 19 mulheres e 7 homens, ou seja, 73\% das associadas são mulheres.

Em artesanato são produzidos: bonecas, bolsas, aventais com retalhos de tecidos; colares, pulseiras de bambu (Bambusoideae) e bijuteria; acessórios para a cozinha de crochê $\hat{e}^{2}$, tricô e patchwork; produtos religiosos de pau-brasil (Paubrasilia echinata), pérola, pedras e cristal; miniplantas e brinquedos didáticos infantis de tecido.

E em alimentação são produzidos ou ofertados: castanha de caju natural, cone trufado, bolo de castanha, gastronomia típica italiana (canneloni, rondeli

\footnotetext{
O crochê, o tricô e o patchwork são trabalhos artesanais, contudo, há algumas diferenças. O crochê e o tricô são parecidos em suas técnicas de enlaçar fios de maneira sincronizada com o auxílio de uma agulha de diversos tamanhos já o patchwork é construído com diversos retalhos de tecido (CULTURA MIX, 2011).
} 
e nhoque), tapioca artesanal com diversos sabores (salgados e doces), água de coco e suco natural de frutas, pastel de milho e trigo diversos sabores (salgados e doces), suco natural de frutas, refrigerante, crepe suíço, bolo de milho verde fresco, bala de coco, bala baiana e trufas.

Vale destacar a concentração da atuação das mulheres da AAT no artesanato. Assim, a partir dessa particularidade recorre-se ao contexto histórico das mulheres no mundo do trabalho por meio de uma ótica que possibilite analisar as atividades artesanais realizadas por elas.

Ao longo das histórias hegemônicas contadas, as mulheres muitas vezes ocuparam um local marginalizado e invisibilizado (SCOTT, 1995; BEAUVOIR, 1949). Os trabalhos domésticos e de produção realizados por elas não são reconhecidos, mesmo estes sendo fundamentais para a manutenção da sociedade e de suas relações, na maioria das vezes foram marginalizados pelo sistema hegemônico (HIRATA; ZARIFIAN, 2009; MELO; CASTILHO, 2009; ÁVILA, 2006).

Federici (2017) menciona que a fortificação do sistema capitalista foi constituída pela mercantilização dos corpos das mulheres, seja para criação de novas mãos de obra ou pela não remuneração de muitos trabalhos realizados por elas. Paralelamente a esse período ocorreu uma das maiores perseguições às mulheres com a caça às bruxas durante os séculos XVI e XVII, o que levou a uma diminuição do protagonismo social das mulheres em diversas atividades exercidas por elas, seja com as curandeiras ou com as parteiras, construindo muitas vezes um sentido nefasto para os trabalhos realizados pelas mesmas (FEDERICI, 2017).

No Brasil, o processo de invasão e colonização por membros de países europeus contribuiu para uma maior marginalidade dos corpos das mulheres, fortificando, assim, o caráter androcêntrico e patriarcal existente até os dias atuais, interferindo nas relações sociais de sexo, raça e classe (FEDERICI, 2017). O Estado brasileiro teve seus pilares econômicos e sociais fincados na exploração e invisibilidade do trabalho doméstico das mulheres, visto que na maioria das vezes mesmo que as mulheres acabem se inserindo mais no mercado de trabalho, sua participação ainda se torna instável, informal e com menores remunerações comparadas com os homens, dificultando o alcance de cargos de maiores níveis (SOUSA; GUEDES, 2016).

As atividades produtivas mais realizadas por mulheres normalmente são relacionadas ao setor de serviços, com atividades constantes, cansativas e entediantes, criando assim uma divisão sexual do trabalho (LIMA et al., 2007). 
Dessa forma, a divisão sexual do trabalho é uma estrutura social que separa os trabalhos de acordo com os sexos, onde historicamente os homens foram destinados ao ambiente produtivo e a mulher ao reprodutivo, o que proporcionou aos homens os trabalhos com maiores remunerações e reconhecimento financeiro e social (HIRATA; KERGOAT, 2007).

As mulheres da associação possuem a média de idade de 56 anos, sendo que a maioria trabalha com o artesanato há mais de dez anos. A renda obtida com o artesanato é na maior parte a única que as mulheres possuem e serve como complementação à renda familiar. Algumas mulheres são casadas e os maridos possuem maior remuneração e outras são viúvas ou divorciadas que dependem de rendas externas, como pensões.

Durante as conversas de convívio que as pesquisadoras tiveram com as mulheres associadas, registraram-se relatos de mulheres que abondaram estudos e carreiras profissionais por conta do casamento e foram morar em Itajubá seguindo o marido. Algumas relataram que são apoiadas pelo marido e família, outras disseram que não, e que seus cônjuges acham o trabalho artesanal que elas realizam sem expressividade econômica.

Portanto, as associadas da AAT, além da não visibilidade, muitas vezes enquanto mulheres, sofrem também com a marginalidade do trabalho artesanal. Segundo Silva (2015), o artesanato é geralmente realizado dentro dos espaços domésticos, não encaixando nas lógicas do sistema capitalista, com a produção em massa e por ser uma atividade exercida em sua maioria por mulheres. Desse modo, o trabalho artesanal passa por uma "dupla exclusão".

Ferreira Júnior, Nascimento e Figueiredo (2016), no seu trabalho com as artesãs dos brinquedos feitos com miriti, destacaram a necessidade do apoio do poder público para a valorização do trabalho artesanal, realizado por mulheres. Além disso, os autores ressaltaram que todo o histórico de desvalorização e invisibilidade do trabalho artesanal e do trabalho das mulheres acabou provocando a ausência da mulher artesã nos espaços de decisões públicas.

Nesse sentido, vale a pena abordar a situação ocorrida com a AAT, onde as associadas ficaram mais de um ano tentando agendar uma reunião com o prefeito de Itajubá com o objetivo de compreender o motivo pelo qual elas não poderiam mais realizar a feira na praça central do município, uma vez que era lá o melhor local para comercialização. As associadas elaboraram carta, protocolaram pedido de reunião e todas as tentativas de diálogo foram negadas, e por fim, a única explicação que chegou até elas foi que os donos de comércio do entorno da praça tinham reclamado e não gostariam que houvesse a feira no local. 


\section{FEIRAS E SUAS EXPRESSÕES CULTURAIS, SOCIAIS E ECONÔMICAS}

As feiras surgem como um espaço de interação social, econômica e política, para a geração de renda, formação de espaços culturais e em alguns locais até mesmo tornam-se pontos turísticos (GRIMM; SAMPAIO; PROPORICK, 2018). Grimm, Sampaio e Proporick (2018) mencionam que as feiras representam para algumas pessoas a sua maior alternativa de fonte de renda. Os autores ainda destacam que as feiras urbanas têm "[...] a capacidade local de mobilizar capital social para buscar perspectivas de desenvolvimento pautado em uma lógica menos dependente daquelas formas de produção o intensivas em recursos de capital” (GRIMM; SAMPAIO; PROPORICK, 2018, p. 39).

A feira realizada pela AAT, por sua vez, representa um espaço alternativo de trabalho e renda para as associadas, enquadrando-se na descrição dos autores. Contudo, a feira da AAT é também um espaço público de promoção da sociabilidade e das memórias, além de um espaço político de organização e exercício da cidadania.

No entanto, é importante destacar que nem todo mundo acessa da mesma maneira os espaços públicos. Rodrigues (2017) menciona que os espaços das cidades se tornaram impessoais e mercadológicos, criando mais "valores de trocas" do que "valores de uso" e excluindo diversos sujeitos sociais da sua ocupação e até mesmo criação. $\mathrm{O}$ apagamento das mulheres no planejamento e execução das cidades auxilia na formação de locais cercados por violências e vulnerabilidades (RODRIGUES, 2017). Jacobs (2009) complementa mencionando que é preciso ter uma visão mais inclusiva, observando todos os detalhes existentes nos locais públicos.

Lefèbvre (2012) traz a reflexão de que as cidades possuem uma ligação concreta com a sociedade e que a transformação dela pode causar a alteração nos centros urbanos. Harvey (2014) complementa mencionando que o direito à cidade não se restringe somente a estar em determinado espaço, mas sim de transformá-lo, visto que as cidades, na maioria das vezes, formam um espaço de tensões sociais, culturais e políticas. As mulheres, por suas vezes, têm um papel relevante na ocupação desses locais, pois assim como mencionando anteriormente os homens, em sua maioria, ocuparam os espaços públicos considerados mais importantes, excluindo e silenciando as mulheres.

A feira das mulheres da AAT acontece às sextas e aos sábados na praça Getúlio Vargas, região central da cidade, próxima a escolas, bancos, agências de correios, redes de lojas e supermercados. No entanto, de acordo com o relato 
das associadas, o local em específico onde acontece, a praça, não é o melhor para as vendas dos artesanatos como já descrito nos tópicos anteriores. Segundo as associadas, as condições da praça Getúlio Vargas (Figura 1) são de certa forma precárias, não há banheiros, o calçamento não é uniforme, a iluminação é precária, muitos moradores de rua também ocupam o espaço da praça e os jovens fazem uso de drogas.

Figura 1 - Mapa da praça Getúlio Vargas onde se localiza a feira da AAT

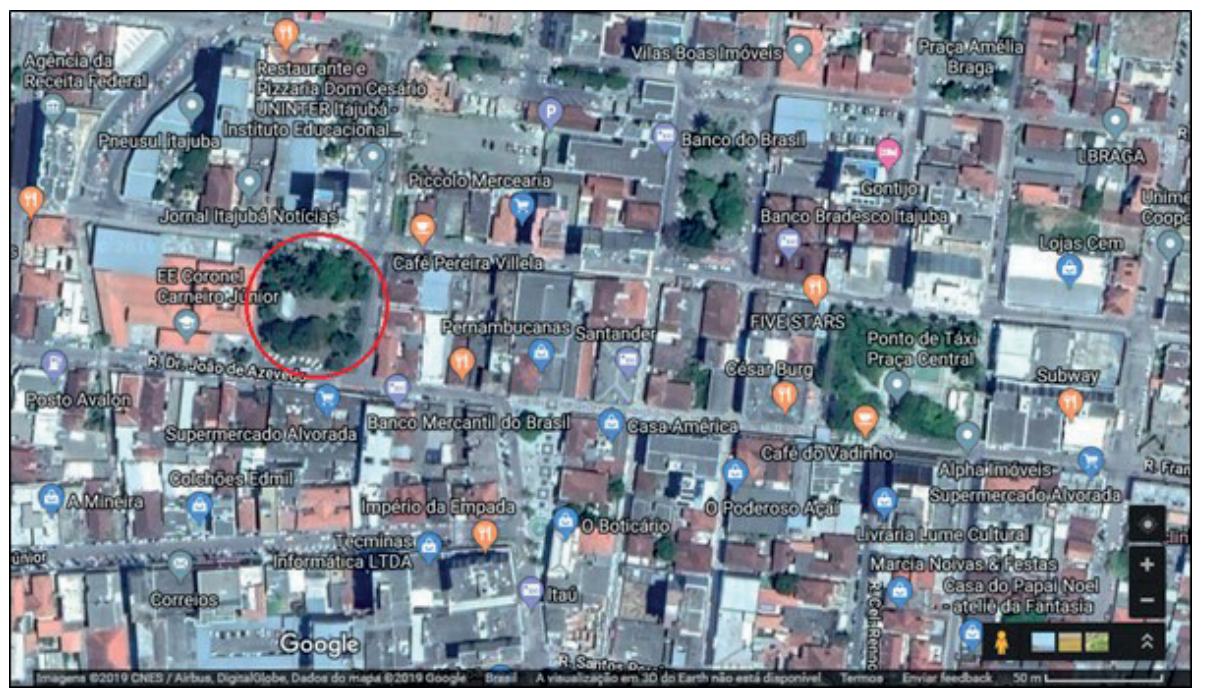

Fonte: Elaborada pelas autoras tendo como base o Google Maps (2019).

Assim como já apontado, a exclusão das mulheres na formação dos espaços públicos acaba gerando espaços de violência (RODRIGUES, 2017). E essa violência e apagamento podem ser observados no espaço descrito pelas mulheres da AAT, que em diversos momentos relataram certo desconforto não só financeiro, mas também de segurança quanto à ocupação do espaço público. Tendo em conta que a participação das mulheres da AAT, na maioria das vezes, foi dificultada ou silenciada, fato este que se faz perpendicular à não participação em outros espaços que possam dialogar com as demandas das associadas, criando assim alguns conflitos.

Por outro lado, a praça Theodomiro Santiago, na qual as associadas gostariam de realizar periodicamente a feira, tem localização central na cidade, pois está de frente para a rua que vai até a igreja matriz e é em um local com diversos estabelecimentos comerciais fixos. A referida praça possui equipamentos como: banheiros, uma concha acústica, uma fonte grande de água e um calçadão 
que liga as principais ruas comerciais. A Figura 2 evidencia a localização da praça Theodomiro Santiago e sua distância em relação à praça Getúlio Vargas, onde está situada a feira da AT'T.

Figura 2 - Mapa da distância entre a praça Getúlio Vargas e a praça Theodomiro Carneiro Santiago

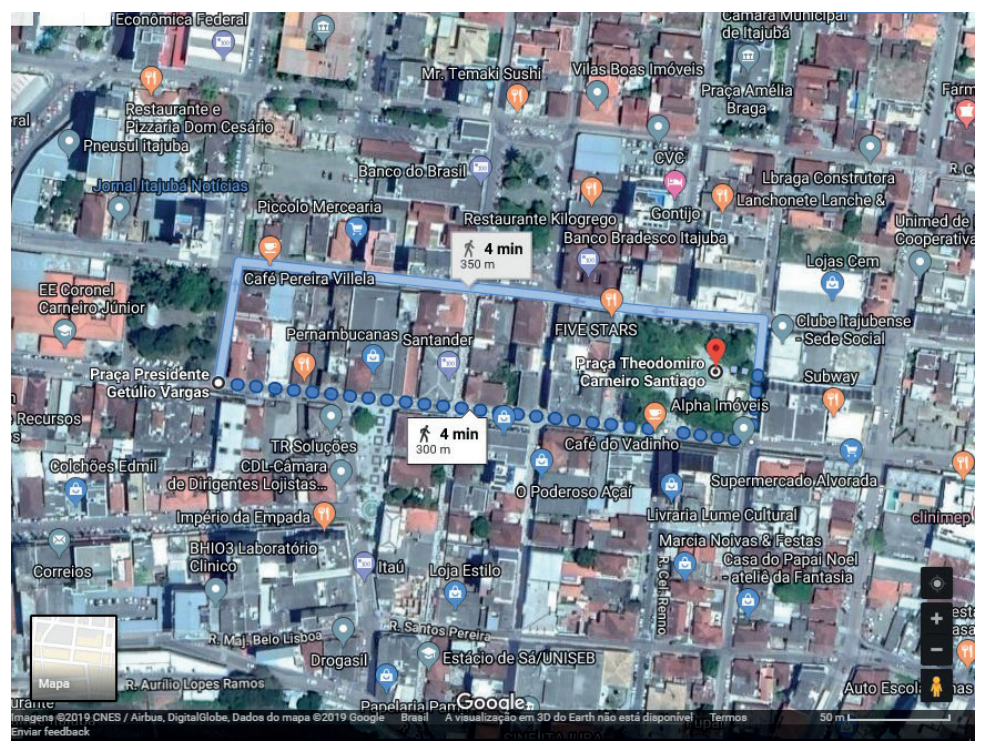

Fonte: Elaborada pelas autoras tendo como base o Google Maps (2019).

As associadas alegam que na praça Theodomiro Santiago as pessoas vão com tempo para passear e contemplar o local, usufruindo-o como um espaço de lazer, diferente do antigo espaço que as pessoas utilizam apenas como um local de passagem.

Na praça Theodomiro Santiago os comércios locais, em sua maioria, são do setor de alimentação, como bares, restaurantes, sorveterias e lanchonetes. De outros setores, há uma agência lotérica, uma agência de viagens, dois estabelecimentos de móveis, um de telefonia e por fim um relacionado com internet.

Mesmo as mulheres alegando um maior interesse e demanda para a mudança de local para a realização da feira, o poder público, na maioria das vezes, alegou a proibição da realização da feira na praça Theodomiro Santiago, às reclamações dos comerciantes locais, uma vez que foi questionado aos comerciantes sobre percepções que eles tinham sobre a feira.

Com isso e observando um elo de conflito de interesses entre a AAT, a prefeitura e os comércios locais, elaborou-se um questionário com o objetivo de tentar compreender o real motivo dos comerciantes para a não realização da feira. 
A primeira questão foi de qual maneira a feira influenciava no fluxo de circulação de pessoas dentro dos comércios locais, e a maioria dos respondentes relataram que, nos dias em que havia a feira da AAT, ocorria um aumento significativo nos estabelecimentos. Esses dados podem ser mais bem observados no Gráfico 1.

Gráfico 1 - Respostas dos comerciantes sobre o movimento

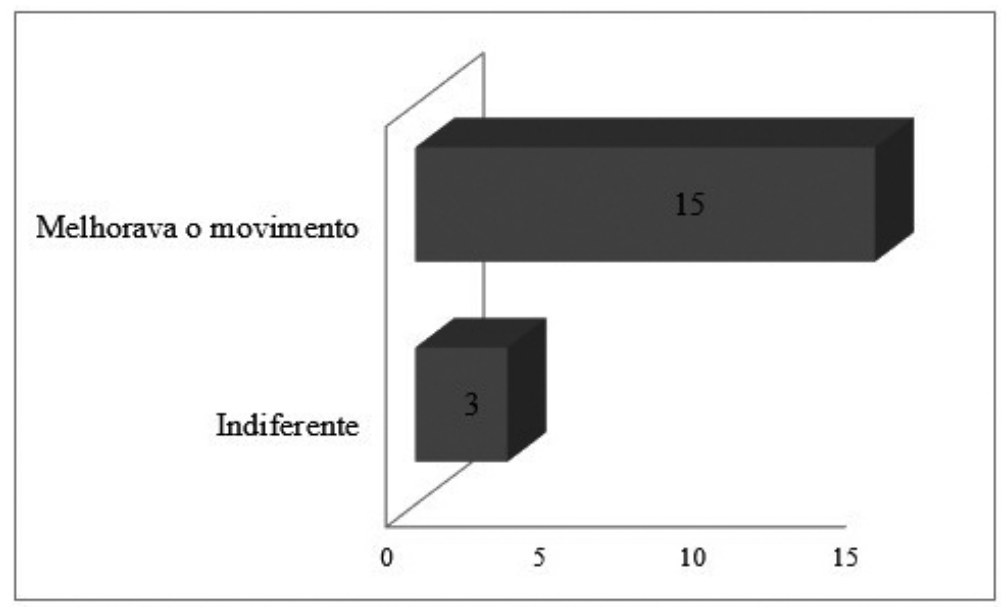

Fonte: Elaborado pelas autoras.

De acordo com os comerciantes locais, a feira da AAT atraía mais clientes para eles, pois diversificava a praça com atividade cultural e tornava o ambiente ainda mais familiar. Assim, os comerciantes locais, em sua maioria, relataram que a feira da AAT poderia ocorrer mais vezes na praça Theodomiro Santiago. Somente um dos entrevistados mencionou que deveria haver uma restrição de frequência, podendo ocorrer somente uma vez por mês.

Um dos comerciantes relatou: "Itajubá é rico em produtos artesanais, têm que ser valorizados e dadas as chances para serem bem vendidos" (informação verbal) ${ }^{3}$. Outro comerciante local mencionou que a presença da AAT na praça Theodomiro possibilitaria uma maior visibilidade para o local. Essa relação de troca e visibilidade também pode ser observada pela pergunta referente ao consumo das associadas da AAT nos estabelecimentos comerciais locais, para a qual 77,7\% dos comerciantes mencionaram que há consumo e que também havia uma parceria com a AAT, onde as associadas indicavam o comércio para os clientes.

$\mathrm{Na}$ pesquisa realizada por Araújo e Ribeiro (2018) sobre as feiras livres do Jequitinhonha, os resultados sobre a percepção dos comerciantes

3 Informação concedida por João, comerciante, em outubro de 2018. 
próximos de onde ocorre a feira foram parecidos. De acordo com os autores, "os comerciantes pesquisados apontaram uma estimativa média de aumento das vendas proporcionadas pelas feiras" (ARAÚJO; RIBEIRO, 2018, p. 316) e "sobre a frequência de feirantes nos estabelecimentos, $87 \%$ dos comerciantes apontaram que os vendedores das feiras adquirem produtos em suas instalações" (ARAÚJO; RIBEIRO, 2018, p. 317).

No levantamento dos pontos positivos e negativos sobre a presença da feira da AAT na praça, foram indicados dez aspectos positivos que envolveram desde o aumento da comercialização até a valorização da cultura da cidade (Gráfico 2). No entanto, o fator mais relatado pelos respondentes foi o "aumento da freguesia", o que demonstra a relação positiva da feira da AAT sobre o aumento do fluxo de clientes para os comerciantes fixos nos dias em que ocorre.

Gráfico 2 - Pontos positivos da feira na praça Theodomiro Santiago

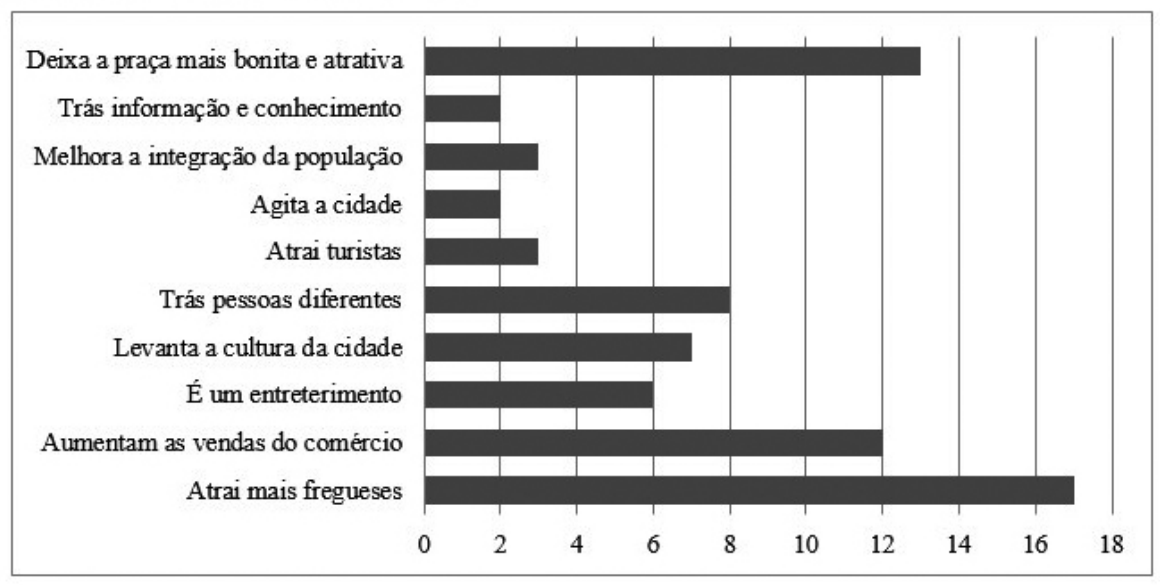

Fonte: Elaborado pelas autoras.

De acordo com o gráfico acima, é importante notar o destaque de dois pontos positivos com a presença a feira da AAT na praça levantados pelos comerciantes, que são a atração de mais fregueses para os comerciantes locais, o que por consequência auxilia na expansão das vendas e a relação turística e cultural que a feira da AAT pode propiciar para o município. Estes dois pontos são destacados pelo Gráfico 2 e pode ser observado também por Ferreira (2017), quando o autor relata que as feiras representam uma relação histórica, cultural e econômica nos contextos em que estão inseridas, esta concepção assessora no desenvolvimento local, no aumento das trocas comerciais e também na ampliação do turismo realizado nas localidades da feira. 
Outro ponto importante a ser analisado é o espaço que compõe a feira. Segundo Almeida e Santos (2019), os espaços em que se realizam as feiras são públicos, pois além de comporem as relações sociais e econômicas com a população em que estão inseridas, também constroem vínculos com o poder público, seja por sua relação territorial ou comercial e turística. Esse encadeamento local também pode ser observado nos elos construídos entre os comerciantes e as associadas da AAT, pois ocorreram somente dois relatos negativos sobre a realização da feira na praça Theodomiro Santiago. Um respondente mencionou que as barracas da feira da AAT não estavam em boas condições, o que tornava a praça um local de não agrado. Já outro comerciante local disse que a falta de organização na distribuição das barracas da AAT atrapalhava a organização espacial da praça.

Como sugestão para as sujeitas da AAT, foi apontado que a prefeitura municipal deveria colaborar com as feirantes para melhorarem as barracas; que deveria haver uma mudança na disposição das barracas da AAT, na qual pudessem ficar de frente para o comércio local. Por fim, foi relatado que as barracas deveriam ocupar a posição central da praça Theodomiro Santiago.

A relação de disputa de interesses entre a prefeitura municipal, as sujeitas da AAT e os comerciantes locais pode auxiliar ou não no desenvolvimento de uma política pública local. Visto que as políticas públicas são de longo prazo, há diversos conflitos existentes entre os sujeitos envolvidos, assim como observado com os atores sociais destacados no texto (SOUZA, 2006; TATAGIBA; ABERS; SILVA, 2018).

Höfling (2001) menciona que os resultados são vistos de diferentes maneiras de acordo com os distintos grupos envolvidos dentro das relações de poder, seja do próprio Estado ou de outros grupos sociais, trazendo a influência de fatores sociais, econômicos e culturais para a formação e a implementação da política pública. Andion et al. (2017) complementam que a formação de um Estado democrático é alicerçada por grupos distintos em torno de um proveito público por meio de feitos coletivos em distintas arenas públicas.

Arenas públicas, segundo Cefaï $(2007,2017)$, são formadas por uma conjuntura problemática. Instituídas por agentes próprios, organizações e instituições que se unem coletivamente para administração de problemas públicos, ou seja, as arenas públicas são locais de disputas e também de relações sociais diversas.

Dialogando com a Associação Artes da Terra, o que muitas vezes pode parecer algo positivo para as sujeitas da AAT, não necessariamente será visto ou pelo comércio local ou pelo poder público. Desse modo, para que haja um equilíbrio nas implementações das políticas públicas, é preciso haver uma maior equidade nos interesses dos envolvidos. 
Por meio desta pesquisa, foi realizado um relatório que foi encaminhado para o poder público municipal, com o objetivo de apresentar outra ótica dos comerciantes locais sobre a presença das sujeitas da AAT na praça Theodomiro Santiago. A entrega do relatório possibilitou que as sujeitas da ATT pudessem marcar uma sessão na Câmara Municipal de Itajubá em 08 de novembro de 2018, juntamente com os vereadores do município. Nesta sessão foi discutida a importância da AAT para o desenvolvimento local e algumas necessidades que a associação possuía. Durante a sessão a presidenta da AAT dialogou com os vereadores sobre a associação. Posteriormente, uma representante da Incubadora Tecnológica de Cooperativas Populares (INTECOOP) explanou sobre a seriedade do relatório, o quanto ele era importante para apresentar outras óticas sobre a AAT e as relações de poder existentes em torno da praça central de Itajubá.

Esse diálogo entre o poder público, a AAT e o comércio local possibilitou que as sujeitas da AAT pudessem ser ouvidas, e propor algumas datas para exporem na praça Theodomiro Santiago, local este que as mulheres alegavam proporcionar um aumento nas vendas dos seus produtos, devido à maior visibilidade. Após a sessão na Câmara dos Vereadores, as sujeitas da AAT puderam expor na praça solicitada em 15 de novembro de 2018, como pode ser observado pela Figura 3.

Figura 3 - Feira da Associação Artes da Terra realizada na praça Theodomiro Carneiro Santiago

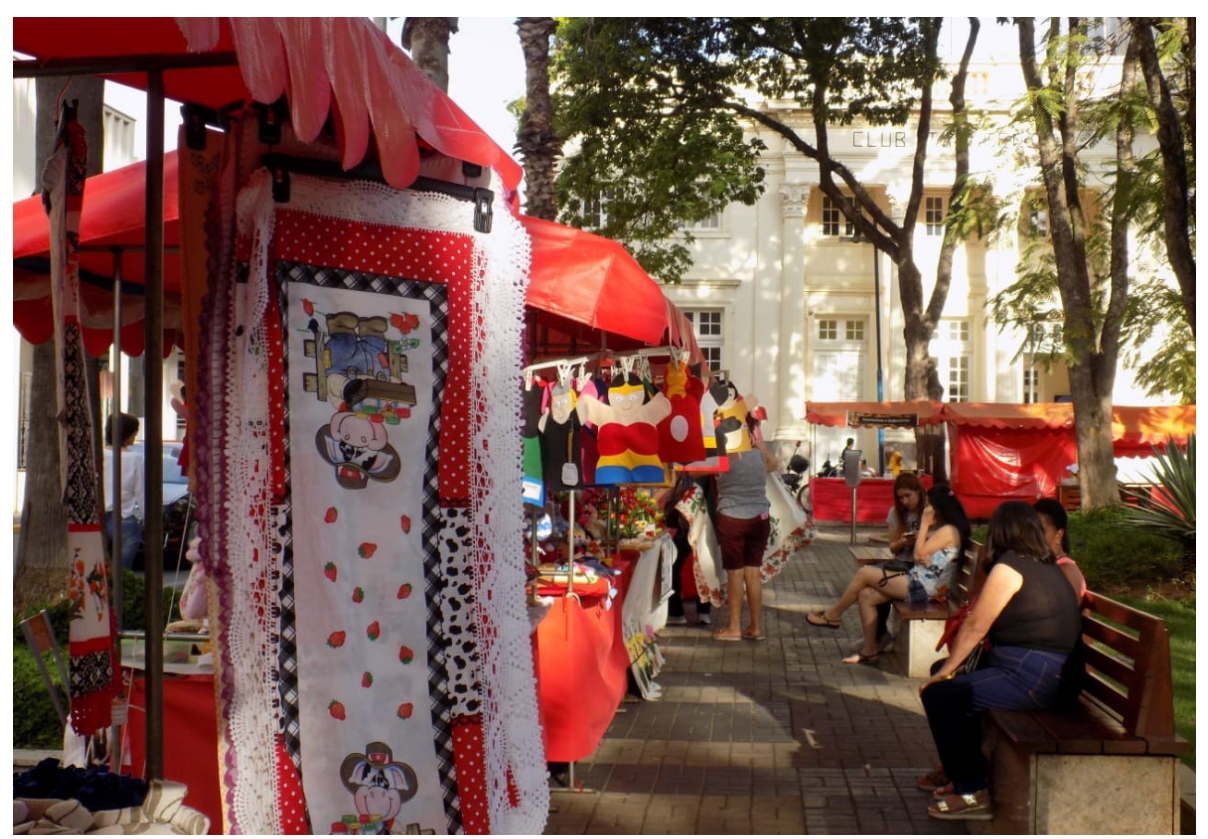

Fonte: Arquivo fotográfico das autoras. 
A Figura 3 traz a imagem da feira das mulheres da AAT já na praça Theodomiro Santiago com as barracas dispostas e organizadas. Tendo em vista a continuidade, durante o ano de 2019, da parceria na exposição no local proposto pela AAT, as mulheres conseguiram começar a expor somente nos dias 09, $10 \mathrm{e}$ 11 de maio.

É importante destacar que o relatório apresentado auxiliou primeiramente uma aproximação das mulheres da AAT com a prefeitura. Todavia, por se tratar de um espaço de disputa, uma arena pública (CEFAÏ, 2017), o espaço não era visto por todos os atores envolvidos como um problema público, ou seja, que somente existiria se fosse algo compreendido como um problema por meio de uma experiência coletiva de todos os envolvidos.

Este fato auxiliou em uma não compreensão tanto da prefeitura como do comércio local para a problemática levantada pelas mulheres da associação. Isto pode ser observado pelo fato de que mesmo com a realização do relatório e trazendo diversos pontos positivos para a mudança do local de comercialização da AAT, as mulheres da associação demoraram muito para conquistar mesmo que por pouco tempo esse direito.

\section{CONSIDERAÇÕES FINAIS}

As mulheres, ao longo da história, na maioria das vezes, ocuparam uma posição subjugada. Este fato se reverberou em diversas esferas sociais. No locus da organização social do trabalho, ocorreu uma divisão sexual, separando e hierarquizando labores tidos como femininos ou masculinos. Já na esfera geográfica e política, houve frequentemente uma exclusão das mulheres na criação dos espaços e das políticas públicas. Essa invisibilidade acaba auxiliando na formação de locais excludentes para as demandas de segurança ou financeira das mulheres.

As mulheres da Associação Artes da Terra não diferem deste contexto e acabam tendo influência da divisão sexual do trabalho. Assim, em seus lares realizam atividades domésticas sozinhas e como o seu trabalho artesanal é realizado no ambiente privado (lar), este labor, na maioria das vezes, acaba não sendo reconhecido pelos seus cônjuges. Ao realizar um paralelo com a exclusão dos espaços públicos este fato é descortinado também na AAT, haja vista a dificuldade do reconhecimento não somente do seu trabalho enquanto mulheres artesãs como também de sujeitas sociais e que necessitam de amparos públicos e sociais. 
Os trabalhos artesanais possuem uma relação de extrema importância cultural, social e econômica nos cenários em que estão inseridos, o que é muitas vezes materializado em feiras. Com isso, a feira da Associação Artes da Terra, atualmente realizada semanalmente na praça Getúlio Vargas, possui um elo consolidado no município de Itajubá. Contudo, foi observado na pesquisa que o local em que hoje é realizada possui diversos problemas, sendo sugerido pelas sujeitas da AAT uma variação periódica para o desenvolvimento da feira em outro local central do município, a praça Theodomiro Santiago.

Diante disto, o trabalho buscou analisar a partir de uma perspectiva feminista a ocupação pública e social da feira das mulheres da Associação Artes da Terra na praça Theodomiro Santiago e a sua interação com o comércio fixo local e o poder público. Foi observado que, devido à exclusão e ao silenciamento das mulheres da associação, se faz dificultosa a aproximação com o poder público, e até mesmo com o comércio fixo local, pois como apresentado ao longo do trabalho, as mulheres estavam há um longo tempo solicitando a mudança com os argumentos de um desfalque financeiro e de falta de segurança no local e mesmo assim muitas vezes havia diversos impasses.

Foi observado que para a maioria dos comerciantes locais há um posicionamento positivo para a realização, pois muitos alegaram que atraía mais clientes e turistas tanto para o seu estabelecimento como para o município. Contudo, dois estabelecimentos trouxeram pontos negativos para a instalação da feira da AAT na praça Theodomiro Santiago, eixos que podem ser inflexionados com as relações políticas do município, como o incentivo de melhoria das barracas da AAT, que até momento estava com uma singela demora. Este fato auxilia na importância desse trabalho, visto que o local da feira da AAT é público e demanda a interação de outros sujeitos e elementos sociais e econômicos envolvidos, como o comércio local e o poder público.

Esse encadeamento social e econômico pôde possibilitar a realização de um relatório de pesquisa que foi apresentado durante a sessão na Câmara Municipal. Essa apresentação auxiliou em uma aproximação maior entre as sujeitas da AAT e o poder público, que por fim pode amenizar a lacuna existente anteriormente, conquistando parcialmente demandas até o momento levantadas, como a realização da feira na praça Theodomiro Santiago, aprovada pela maioria dos comerciantes locais.

Portanto, o estreitamento entre o poder público, a Associação Artes da Terra e os comerciantes locais pode moderadamente amenizar as disputas envolvidas entre ambos, e canalizar os reais interesses e demandas, visto que 
tanto as sujeitas da AAT como a maioria dos comerciantes locais desejam a realização da feira devido a sua importância cultural e econômica para o local. Assim, após a realização do relatório e a sua apresentação para o poder público, essa demanda pode enfim ser materializada.

Cabe destacar que é preciso de fato uma transformação social ressignificando os espaços públicos e tornando vivas as cidades. Essa mudança não é construída facilmente, pois a sociedade está estruturada pelas bases das opressões de gênero, raça e classe. E para isso, é necessário um trabalho de toda a sociedade, a fim de incluir e de fato promover um ambiente mais inclusivo e seguro para todas e todos.

\section{REFERÊNCIAS}

AAT. Regimento interno de funcionamento. Itajubá: AAT, 2017.

ABL. Vocabulário Ortográfico da Língua Portuguesa. 5. ed. Rio de Janeiro: ABL, 2009.

ANDION, C. et al. Sociedade civil e inovação social na esfera pública: uma perspectiva pragmatista. Rev. Adm. Pública, Rio de Janeiro, v. 51, n. 3, p. 369-387, jun. 2017.

ALMEIDA, J.; SANTOS, F. A feira livre de Irará: uma análise cultural. Pontos de Interrogação, Alagoinhas, v. 9, n. 1, jan.-jun., p. 227-243, 2019.

ARAUJO, A. M.; RIBEIRO, E. M. Feiras e desenvolvimento: impactos de feiras livres do comércio urbano no Jequitinhonha. Revista Brasileira de Planejamento e Desenvolvimento, Curitiba, v. 7, n. 2, p. 300-327, 2018.

ÁVILA. M. B. O tempo do trabalho produtivo e reprodutivo na vida cotidiana. Revista da ABET, João Pessoa, vol. IX, n. 2. p. 53-70, 2010.

BEAUVOIR, S. O segundo sexo: a experiência vivida. Trad. de Sérgio Milliet. São Paulo: Difusão Europeia do Livro, 1949.

CEFAÏ, D. Pourquoi se mobilise-t-on?: les théories de l'action collective. Paris: Éditions La Découverte, 2007.

CEFAÏ, D. Públicos, problemas públicos, arenas públicas...: o que nos ensina o pragmatismo (Parte 1). Novos estud. CEBRAP, São Paulo, v. 36, n. 1, p. 187-213, mar. 2017 
CULTURA MIX. Diferenças entre crochê, tricô, patchwork e artesanato. Cultura Mix, São Paulo, 2011. Disponível em: https://artesanato. culturamix.com/curiosidades/diferencas-entre-croche-trico-patchwork-eartesanato $\#: \sim$ :text $=\mathrm{O} \% 20$ tric $\% \mathrm{C3} \% \mathrm{~B} 4 \% 20 \% \mathrm{C} 3 \% \mathrm{~A} 9 \% 20$ parecido $\% 20$ com,padr $\%$ C3\%A3o $\% 2$ C $\% 20$ estas $\% 20 t \%$ C3\%A9cnicas $\% 20$ possui $\% 20$ suas. Acesso em: 13 ago. 2020.

FEDERICI, S. O calibã e a bruxa: mulheres, o corpo e a acumulação primitiva. São Paulo: Elefante Editora, 2017

FERREIRA, T. B. Comunicação e marketing: um estudo das interações comunicacionais entre feirantes e fregueses na feira livre de Paripiranga-BA. 2017. 167 f. Dissertação (Mestrado em Comunicação) - Programa de Pós-Graduação em Comunicação, Universidade Federal de Sergipe, São Cristóvão, 2017.

FERREIRA JÚNIOR, A.; NASCIMENTO, L. T. L; FIGUEIREDO, S. L. Mulheres, papéis sociais e processos criativos entre artesãs de brinquedos de miriti. Novos Cadernos NAEA, Belém, v. 19, n. 3, p. 153-162, dez. 2016.

GOOGLE MAPS. Imagem de satélite. Google Maps, [S. l.], 2019. Disponível em: http://maps.google.com. Acesso em: 20 fev. 2019.

GRIMM, I. J.; SAMPAIO, C. C; PROCOPICK, Mario. Encadeamento ecossocioeconômico e gestão urbana: um estudo das feiras livres na cidade de Curitiba (PR). Novos Cadernos NAEA, Belém, v. 21, n. 1, p. 35-56, jul. 2018.

HARAWAY, D. Saberes localizados: a questão da ciência para o feminismo e o privilégio da perspectiva parcial. Cadernos Pagu, [S. l.], n. 5, p. 7-41, 1995.

HARDING, S. Gênero, democracia e filosofia da ciência. RECIIS: R. Eletr. de Com. Inf. Inov. Saúde, Rio de Janeiro, v. 1, n. 1, p. 163-168, 2007.

HARVEY, D. Cidades rebeldes: do direito à cidade à revolução urbana. São Paulo: Martins Fontes, 2014.

HIRATA, H.; KERGOAT, D. Novas configurações da divisão sexual do trabalho. Cadernos de Pesquisa, São Paulo, v. 37, n. 132, p. 595-609, 2007.

HIRATA, H.; PHILIPPE, Z. Conceito de trabalho. In: HIRATA, H.; LABORIE, F.; LE DOARÉ, H.; SENOTIER, D. (org.). Dicionário crítico do feminismo. São Paulo: Edunesp, 2009. p. 251-256.

HÖFLING, E. M. Estado e políticas (públicas) sociais. Cadernos CEDES, Campinas, v. 21, n. 55, p. 30-41, nov. 2001. 
IBGE. Cidades: Itajubá. IBGE, Rio de Janeiro, 2018. Disponível em: https:// cidades.ibge.gov.br. Acesso em: 02 fev. 2019.

JACOBS, J. Morte e vida de grandes cidades. 2. ed. São Paulo: Martins Fontes, 2009.

LEFÈBVRE, H. O direito à cidade. Lisboa: Estúdio, 2012.

LEITE, R. P. Modos de vida e produção artesanal: entre preservar e consumir. In: CAVALCANTI, C. (ed.). Olhares itinerantes: reflexões sobre artesanato e consumo da tradição. São Paulo: Artesanato Solidário/Central ArteSol, 2005. p. 27-41.

LEMOS, M. E. S. O artesanato como alternativa de trabalho e renda: subsídios para avaliação do programa estadual de desenvolvimento do artesanato no município de Aquiraz-CE. 2011. 111 f. Dissertação (Mestrado em Avaliação de Políticas Públicas) - Universidade Federal do Ceará, Fortaleza, 2011.

LIMA, T. M.; HIRATA. H.; NOGUEIRA, C. M.; GOMES, V. L. B. Trabalho, gênero e a questão do desenvolvimento. Revista Políticas Públicas, Brasília, v. 11, n. 2, p. 221-235, jul./dez. 2007.

MELO, H. P.; CASTILHO, M. Trabalho reprodutivo no Brasil: quem faz?. Revista de Economia Contemporânea, São Paulo, v. 13, n. 1, p. 135-158, 2009.

NARVAZ, M. G.; KOLLER, S. H. Metodologias feministas e estudos de gênero: articulando pesquisa, clínica e política. Psicologia em Estudo, Maringá, v. 11, n. 3, p. 647-654, 2006.

PEREIRA, V. G.; PIMENTA, C. A. M.; BELlEZE, G.; SILVA, G. C.; BATTISTON, K. M.; PEREIRA, S. B.; BRITO, T. P. (org.). Levantamento das potencialidades da agricultura familiar e agroecológica das comunidades rurais atingidas pela mineração nos municípios de Conceição do Mato Dentro, Alvorada de Minas e Dom Joaquim, MG. Itajubá: Núcleo Travessia, 2016. 180 p. (Relatório de pesquisa.)

RIBEIRO, E. M. (org.). Feiras do Jequitinhonha: mercados, cultura e trabalho de famílias rurais no semiárido de Minas Gerais. Fortaleza: Banco do Nordeste do Brasil, 2007.

RODRIGUES, C. F. A mulher no espaço público: uma reflexão acerca do processo de urbanização contemporâneo e da (não) participação das mulheres na produção do espaço. In: SEMINÁRIO INTERNACIONAL FAZENDO GÊNERO E MUNDO DE MULHERES, 13., 2017, Florianópolis. Anais [...]. Florianópolis: MM, 2017. p. 1-12. Disponível em: http://www.en.wwc2017.eventos.dype. com.br/resources/anais/1503025557_ARQUIVO_Amulhernoespacopublico_ ClariceFR.pdf. Acesso em: 12 ago. 2019. 
SCOTT, J. Gênero: uma categoria útil de análise histórica. Educação e Realidade, São Paulo, v. 20, n. 2, p. 71-99, 1995.

SILVA, M. A. Abordagem sobre trabalho artesanal em histórias de vida de mulheres. Educar em Revista, Curitiba, n. 55, p. 247-260, jan./mar. 2015.

SOUSA, L. P; GUEDES, D. R. A desigual divisão sexual do trabalho: um olhar sobre a última década. Estudos Avançados, São Paulo, v. 30, n. 87, p. 123-139, ago. 2016.

SOUZA, C. Políticas públicas: uma revisão da literatura. Sociologias, Porto Alegre, ano 8, n. 16, p. 20-45, 2006.

TATAGIBA, L.; ABERS, R.; SILVA, M. K. 2018. Movimentos sociais e políticas públicas: ideias e experiências na construção de modelos alternativos. In: PIRES, R.; LOTTA, G.; OLIVEIRA, V. (org). Burocracia e políticas públicas no Brasil: interseções analíticas. Brasília: IPEA: ENAP, 2018. p. 105-138. 
